\title{
AN AHP COMPARING THE DESIRABLENESS OF MANY ALTERNATIVES WITH ITS AT LEAST NECESSARY SATISFACTION LEVEL FOR EACH CRITERION
}

\author{
Y.Senda, Y.Kameyama and K.Kurashige \\ Department of computer science and systems engineering, \\ Okayama Prefectural University, Soja 719-1197, Japan \\ kame@cse.oka-pu.ac.jp/kura@cse.oka-pu.ac.jp
}

\begin{abstract}
Abstruct : Absolute Measurement Approach, 'grouping' method and Control-alternative method has been proposed about the decision-making problems that contain many alternatives. They have been developed from the traditional AHP. The common merit of their methods is to reduce efforts of decision-maker (DM) about pairwise comparison, because of these methods are not always necessary to compare with all alternatives.

When we have to deal with practical decision-making problems, it is preferable for the selected alternative to satisfy at least necessary level for each criterion. In this report, we propose an advanced AHP, compares the desirableness of many alternatives with its at least necessary satisfaction level for each criterion and isn't always necessary to compare evaluations of all aiternatives.
\end{abstract}

Next, we apply this presented method to decision-making problem about selecting notebook computer, and we confirm the availability of the method.

Keyword: pairwise comparison, $A H P$

\section{INTRODUCTION}

AHP (Analytic Hierarchy Process) has mainly two issues for the decision-making problems, which contains many criterion and alternatives. First, it is difficult to execute pairwise comparison for all alternatives (criterion) for DM. Secondly, it is difficult to satisfy the Consistency Index (C.I.). Further decision-making problems actually have many alternatives. So decision-maker (DM) has to takes long time in order to choice the alternatives, and there is a possibility to miss the fine alternative.

Then Satty[1] proposed Absolute Measurement Approach (AM Approach). The others considered for the method divide alternatives to some groups and to compare alternatives in each group, finally compares the alternatives, which is the best in each group. (In this report we called it 'grouping' method). 
Besides control-alternative method was proposed by E.Kinoshita and M.Nakanishi [2][3]. In this method DM selects on one's own a control-alternative from all alternatives at will and compares it with rest alternatives for each criterion about these desirableness. A characteristic of this method is compare only $(\mathrm{n}-1)$ times but relative measurement approach has to be compare $n(n-1) / 2$ times.

Tamura etc [4] proposed idea of the at least necessary satisfaction level in AHP in order to weight evaluation of alternatives by pairwise comparison method.

In this report, we propose an advanced AHP, which weight evaluation of alternatives by comparing the desirableness of many alternatives with only at least necessary satisfaction level for each criterion. The characteristic of presented method is we compared to others and considered in term of the number of times for pairwise comparison and using limitation.

\section{Methodology of Advanced AHP}

The at least necessary satisfaction level is the level of alternative that DM satisfies at least for each criterion. If you were owner of professional baseball team, you want forth batter to hit at least $30 \mathrm{HR}$. This " $30 \mathrm{HR}$ " is the at least necessary satisfaction level for forth batter about batting. Following we show the methodology of advanced AHP.

1) Make the hierarchy structure and compare each criterion. Calculate the weights of all criterions.

2) DM images the at least necessary satisfaction level for each criterion.

3) Compare the at least necessary satisfaction level with each rest aiternatives for each criterion. This compared result about "How much DM satisfies each alternative compared with its at least necessary satisfaction level for each criterion".

4) Calculate the weights of alternatives for each criterion from 3) and weights of criteria from 1). Combine those weights and gain the total weights of all alternatives.

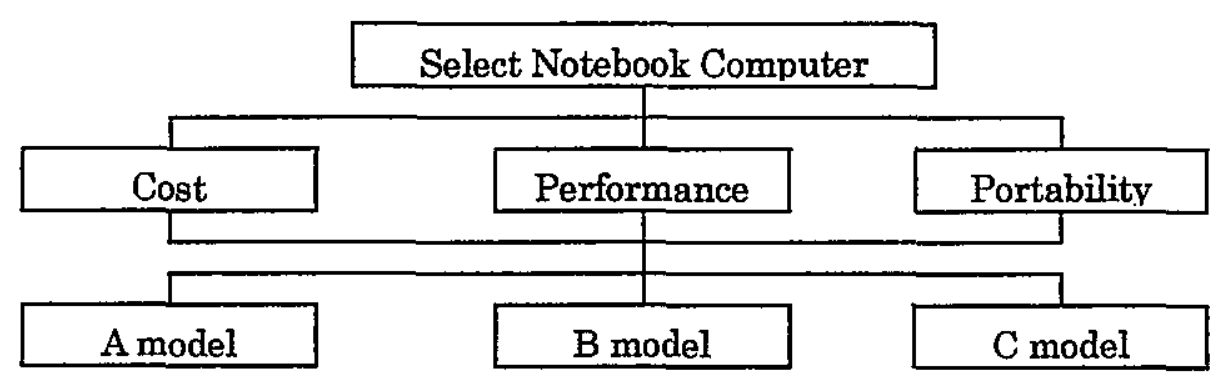

Fig1 Hierarchy Structure on example

Table1 Pairwise comparing result of importance of criteria on the example

\begin{tabular}{|l|c|c|c|c|}
\hline & Cost & Performance & Portability & Weight \\
\hline Cost & 1 & 1 & 2 & 0.400 \\
\hline Performance & & 1 & 2 & 0.400 \\
\hline Portability & & & 1 & 0.200 \\
\hline
\end{tabular}

C.I. $\quad 0.000$ 
Table2 The at least necessary satisfaction level for each criteria on the example

\begin{tabular}{|l|l|}
\hline Criteria & The at least necessary satisfaction level \\
\hline Cost & 250,000 Japanese Yen \\
\hline Performance & CPU166MHz, memory 32MB \\
\hline Portability & A4 size, 3kg \\
\hline
\end{tabular}

Table3 Our representative numerical values which correspond to comparison scales explained by words

\begin{tabular}{|l|l|}
\hline Intensity of importance & Definition (compare former to later) \\
\hline 0 & Equal importance \\
\hline $2(-2)$ & Weak importance of one over another (unimportance) \\
\hline $4(-4)$ & Essential or strong importance (unimportance) \\
\hline $6(-6)$ & Very strong or demonstrated importance (unimportance) \\
\hline $8(-9)$ & Absolutely importance (unimportance) \\
\hline $1(-1), 3(-3), 5(-5), 7(-7)$ & Intermediate values between adjacent scale values \\
\hline
\end{tabular}

Table4 Total weight for each kind of portable computer on the example

\begin{tabular}{|l|c|c|c|c|}
\hline Alternative & Cost $(0.4)$ & Performance(0.4) & Portability (0.2) & Total weight \\
\hline Necessary level & 0 & 0 & 0 & 0.0 \\
\hline A & 6 & -3 & 2 & 1.6 \\
\hline B & -4 & -3 & 6 & -1.6 \\
\hline C & 2 & 2 & -4 & 0.8 \\
\hline
\end{tabular}

Fig2 presents the numbers of pairwise comparison times for example solved by using traditional AHP and at least necessary satisfaction level AHP.

From this figure, we can find that the at least satisfaction level AHP need not do as large number of pairwise comparison times as traditional approach according to increase the number of alternatives.

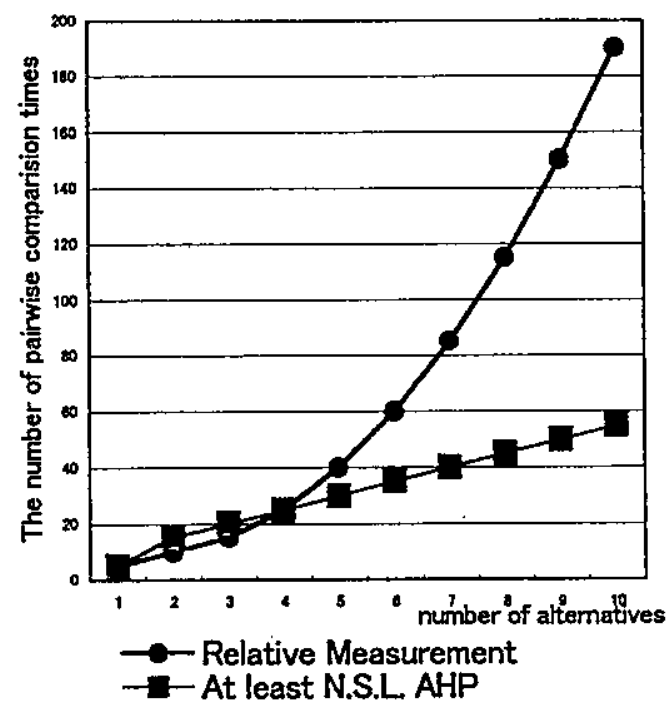

Fig2 Compare times of each method

(Example : Three levels and five criterion structure) 


\section{PRACTICAL EXAMPLE}

We asked for 15 testees to answer questionnaire that based on at least necessary satisfaction level AHP about selection of a kind of notebook computer in order to research the characteristic of this method.

1) First, each testee choices three types of personal computer in preferable order after reading catalog of these personal computers.

2) Second, testees answer the at least necessary satisfaction level for each criterion. (show Table5)

3) Third, testees compare each criterion.

4) Finally, testees compare alternatives with the at least necessary satisfaction level for each criterion. (show Table6)

Tabale7 shows the result of questionnaire. We intended this method can express the likes and dislikes of alternative for each criterion by using the plus and minus of its weight but traditional AHP can not. So DM can express “All alternatives isn't good, but this alternative isn't bad in all alternatives" or "All alternatives is good, and this alternative is excellent" from the result of presented method. After all this method can be judged the degree of preference for all alternatives.

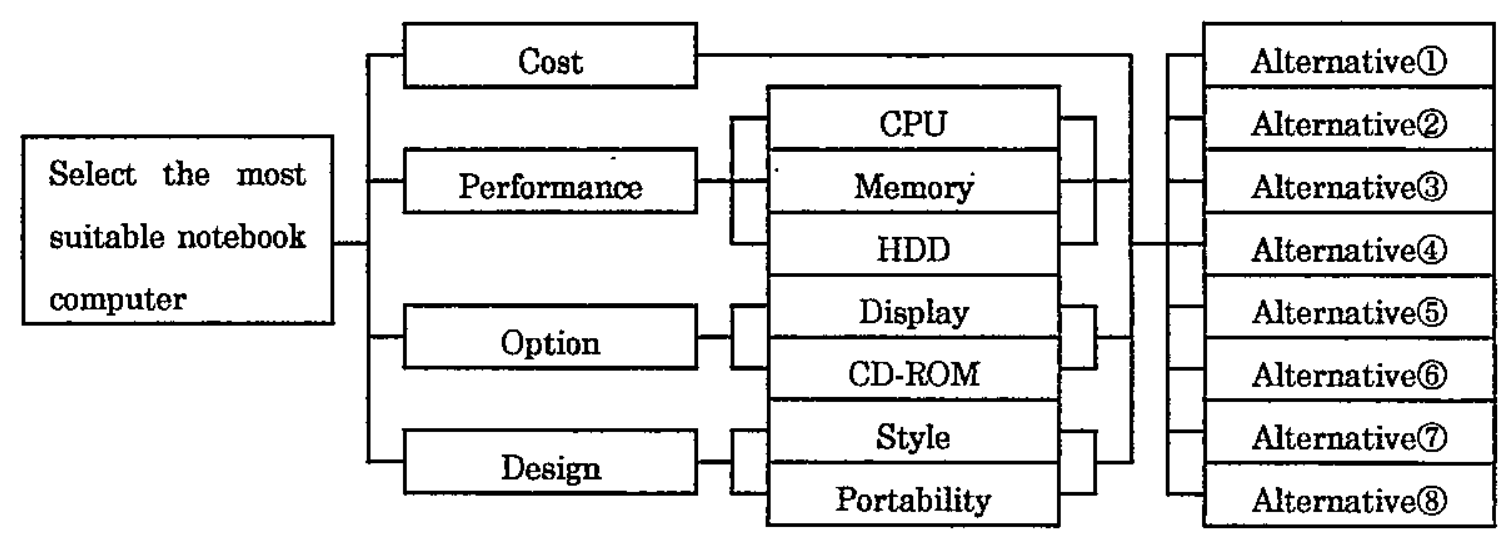

Fig3 Hierarchy Structure of practical questionnaire

Table5 A entry section of practical questionnaire

\begin{tabular}{|l|l|l|}
\hline Criteria & \multicolumn{2}{|l|}{ At least necessary satisfaction level } \\
\hline Cost & Price & \\
\hline \multirow{3}{*}{ Performance } & CPU & \\
\cline { 2 - 3 } & Memory & \\
\cline { 2 - 3 } & HDD & \\
\hline \multirow{2}{*}{ Option } & Display & \\
\cline { 2 - 3 } & CD-ROM & \\
\hline \multirow{2}{*}{ Design } & Style & \\
\hline & Portability & \\
\hline
\end{tabular}




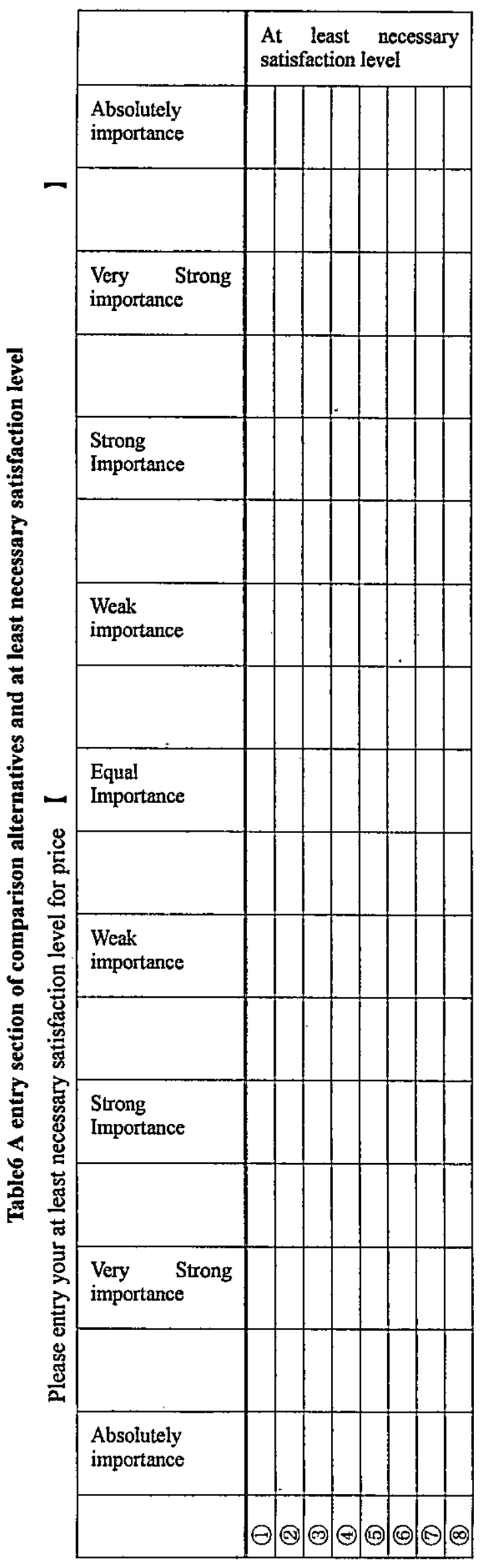

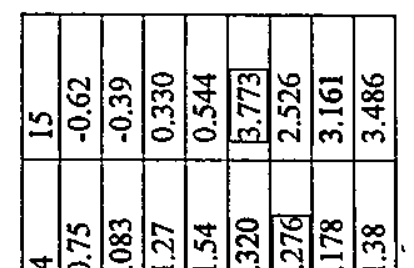

\pm :

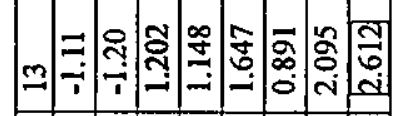

눙 눈

t)

- - 0 : $=0$

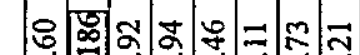

: $=0.0 \div \div \div \div$

.

교 $\cong \simeq \infty$ 웜

है

惫

-

言

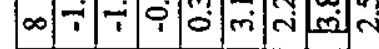

苾

경

岂

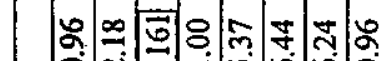

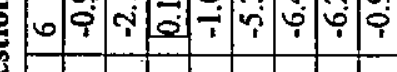

(

案

F. 워워

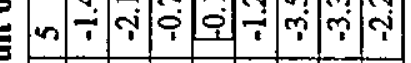

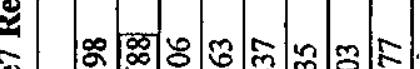

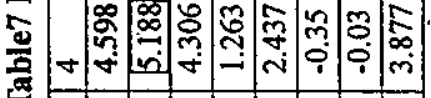

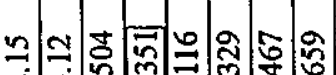

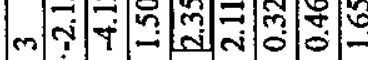

m. F

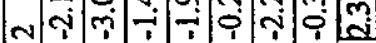

舟 $\infty \approx$

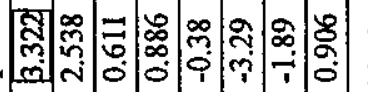

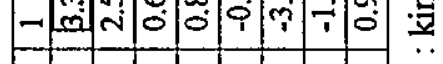

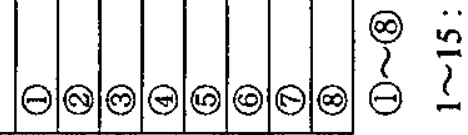

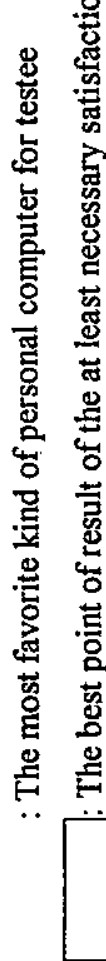


Table8 Characteristics of each method

\begin{tabular}{|c|c|c|}
\hline Method & Merit & Weak point \\
\hline $\begin{array}{l}\text { Absolute } \\
\text { Measurement } \\
\text { Approach }\end{array}$ & $\begin{array}{l}\text { Prevent rank reversal } \\
\text { Prevent redo comparison } \\
\text { Deal with many alternatives }\end{array}$ & $\begin{array}{l}\text { If evaluation basis number is small, then } \\
\text { alternative's estimation is limited, lose suitability } \\
\text { of estimation. Inversely if evaluation basis number } \\
\text { is large, then compare times is increase, lose } \\
\text { conveniently of decision making. }\end{array}$ \\
\hline $\begin{array}{l}\text { 'grouping' } \\
\text { method }\end{array}$ & Deal with many alternatives & $\begin{array}{l}\text { Compare again when new alternative add } \\
\text { Possibility of rank reversal }\end{array}$ \\
\hline $\begin{array}{l}\text { Control } \\
\text { Alternative }\end{array}$ & $\begin{array}{l}\text { Prevent rank reversal } \\
\text { Prevent redo comparison } \\
\text { Deal with many alternatives } \\
\text { Reduce compare time }\end{array}$ & $\begin{array}{l}\text { Using of this method is limited when following } \\
\text { rule is satisfied. } \\
\text { "A weight of criteria is high when control } \\
\text { alternative is excellent about this criteria" }\end{array}$ \\
\hline $\begin{array}{l}\text { Necessary level } \\
\text { AHP }\end{array}$ & $\begin{array}{l}\text { Prevent rank reversal } \\
\text { Prevent redo comparison } \\
\text { Deal with many alternative } \\
\text { Reduce compare time } \\
\text { No rule of control-alternative } \\
\text { method } \\
\text { Express DM's desirableness }\end{array}$ & $\begin{array}{l}\text { It is difficult to image the at least satisfaction level } \\
\text { about subjectively things. }\end{array}$ \\
\hline
\end{tabular}

\section{CONCLUSION}

In this report, we proposed an advanced AHP that first DM image the at least necessary satisfaction level of alternative for each criterion, second compare this level with the desirableness of many alternatives, finally DM can select totally the best alternative from them.

This method has been suitable applied to the selection problem for a kind of notebook computer from many alternatives.

For later, we expect this method may will be applied to the problems with the customer's test of new products that need to know which alternative should be improved and to test as much as alternatives and as many as people.

\section{REFERENCES}

[1]Satty, T.L, "The Analytic Hierarchy Process", McGraw-Hill, New York, (1980)

[2]E.Kinoshita and M.Nakanishi, "A PROPOSAL OF MEW VIEWPOINT IN ANALYTIC HIERARCHY PROCESS", Journal of Japan Society of Civil Engineering, No13,(1996),pp153 160

[3]E.Kinoshita, "Sonshi no heihou no suugaku moderu"(Japanese), kodan-shya,(1998),pp155 165

[4]H.Tamura, S.Takahashi, I.Hatono and M.Umano, "On a descriptive Analytic Hierarchy Process (DAHP) for Modeling the Legitimacy of Rank Reversal", Journal Of Operations Research Society of Japan, Vol.41, No.2, (1998) 